\title{
Two Community Clusters of Legionnaires' Disease Directly Linked to a Biologic Wastewater Treatment Plant, the Netherlands
}

\author{
Anna D. Loenenbach, Christian Beulens, \\ Sjoerd M. Euser, Jeroen P.G. van Leuken, \\ Ben Bom, Wim van der Hoek, \\ Ana Maria de Roda Husman, \\ Wilhelmina L.M. Ruijs, Alvin A. Bartels, \\ Ariene Rietveld, Jeroen W. den Boer, \\ Petra S. Brandsema
}

A biologic wastewater treatment plant was identified as a common source for 2 consecutive Legionnaires' disease clusters in the Netherlands in 2016 and 2017. Sequence typing and transmission modeling indicated direct and longdistance transmission of Legionella, indicating this source type should also be investigated in sporadic Legionnaires' disease cases.

$\mathrm{I}$ Tn autumn 2016, six reported cases of Legionnaires' dislease (LD) were linked to the town of Boxtel, the Netherlands. In the second half of 2017, eight more cases were identified among residents of the town. During 2003-2015, only 1 non-travel-related LD case was reported in Boxtel. In 2016 and 2017, the cases were investigated to determine if they were linked to a common source. We describe the epidemiologic, environmental, and microbiologic investigation of these 2 Legionella clusters.

\section{The Study}

We defined cases as Legionella pneumonia in a person with illness meeting the European Union case definition (1) who resided in or visited Boxtel 2-14 days before disease onset during 2016-2017. The 2016 cluster (cluster 1) consisted of 4 residents and 2 nonresidents who work in the industrial

Author affiliations: European Centre for Disease Prevention and Control, Stockholm, Sweden (A.D. Loenenbach); National Institute for Public Health and the Environment, Bilthoven, the Netherlands (A.D. Loenenbach, J.P.G. van Leuken, B. Bom, W. van der Hoek, A.M. de Roda Husman, W.L.M. Ruijs,

A.A. Bartels, P.S. Brandsema); Municipal Health Service Hart voor Brabant, 's-Hertogenbosch, Tilburg, the Netherlands (C. Beulens, A. Rietveld); Regional Public Health Laboratory Kennemerland, Haarlem, the Netherlands (S.M. Euser, J.W. den Boer); Utrecht University, Utrecht, the Netherlands (A.M. de Roda Husman) area of Boxtel. The onset of disease symptoms ranged from October 28 to December 11, 2016. During July 10-November 3, 2017, seven more cases (all in Boxtel residents) occurred (cluster 2) (Figure 1). Further investigation identified another case, in a person who visited Boxtel 5 days before symptom onset.

The median age of the 14 patients was 72 years (range 51-93 years); 8 patients (57\%) were male (Table 1). All 14 patients were hospitalized, 7 (50\%) were smokers, and 11 (79\%) had co-morbid conditions.

Patient interviews did not identify any common exposure, and none of the case-patients had recently traveled abroad. Mapping cases based on the patients' residential postal code and prevailing wind direction (mainly southwest during individual incubation times [https://www. knmi.nl]) indicated that the source could be within the industrial area of Boxtel.

In November 2016, environmental samples were collected at several potential sources, including a fountain and 5 wet cooling towers (WCT) (Table 2). However, no Legionella were detected in these samples. The emergence of new LD cases in 2017 led to the reexamination of these locations, along with identification of additional potential sources, including a biologic wastewater treatment plant (BWTP) in the industrial area. The installation, which was transformed into a BWTP for energy production in summer 2015 , consisted of 3 ponds with different degrees of aeration. All ponds tested positive for L. pneumophila (Table 2). Because the BWTP effluent drains to the municipal wastewater treatment plant (MWTP), located in the northwest of Boxtel, and discharges onto the Dommel River after treatment, these locations were also sampled. Subsequently, 2 air scrubbers near the BWTP were tested, and air above the BWTP was sampled.

All 14 cases were confirmed by urine antigen testing (Table 1). Clinical and environmental isolates were genotyped by using sequence-based typing (SBT), as previously described $(2,3)$, and compared with the European Working Group for Legionella Infectious Sequence-Based Typing Database (http://www.hpa-bioinformatics.org.uk/legionella/legionella_sbt/php/sbt_homepage.php). An identical sequence type (ST), ST1646, was found in 5 patients ( 2 in cluster 1 and 3 in cluster 2) (Figure 1). Two other sequence types were found for 2 patients in cluster 1 (Table 1). SBT of the environmental 


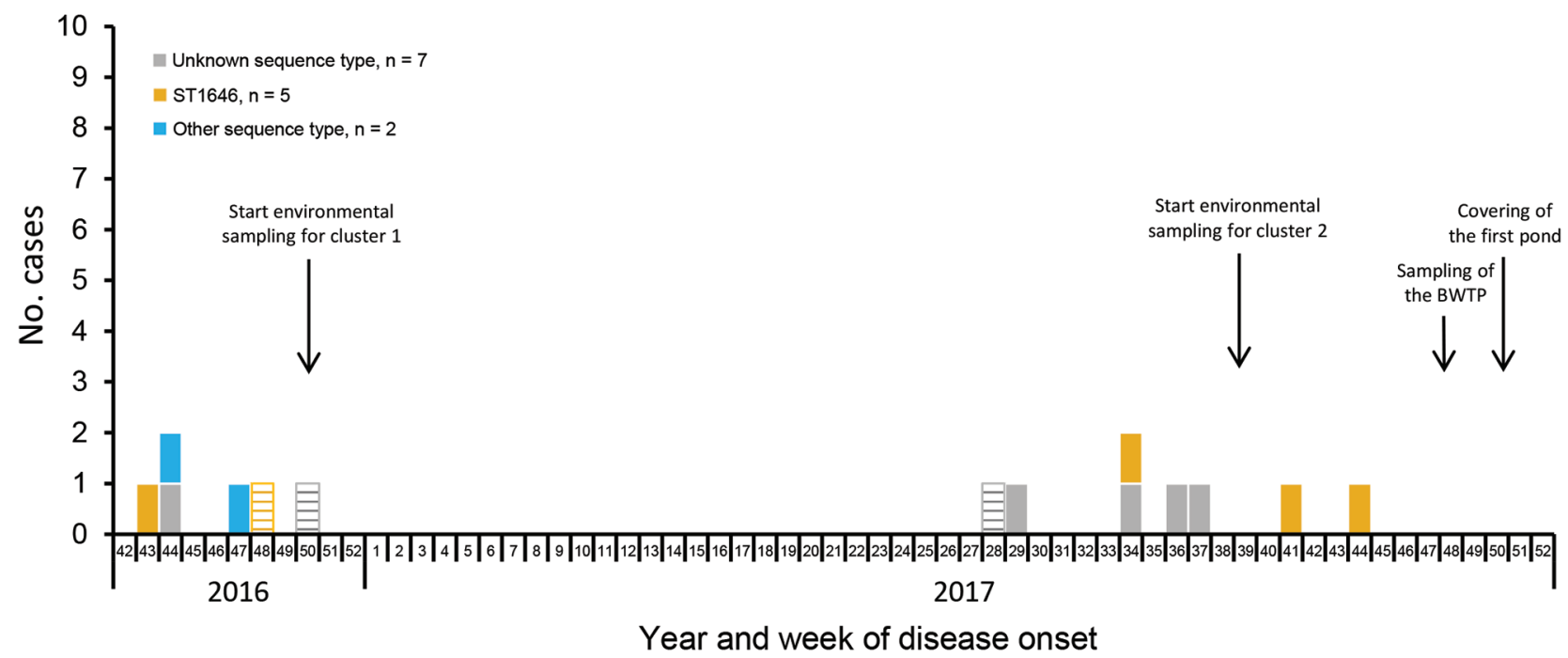

Figure 1. Legionnaires' disease cases, by sequence type and week of disease onset, Boxtel, the Netherlands, October 2016-December 2017. BWTP, biologic wastewater treatment plant; ST, sequence type.

isolates from the BWTP, the MWTP, and the river also identified ST1646. This sequence type was also detected in isolates from air sampled above the BWTP pond with the most aeration. Legionella was not detected in the other sampled locations (Table 2).

We used a transmission model for rapid detection of potential environmental sources of airborne pathogens in outbreak investigations $(4,5)$, which was used for Legionella for the first time and applied to the data collected for the outbreak investigation in Boxtel. The model calculated a measure of risk (MR) based on patients' residential addresses in Boxtel, date of illness onset, and population density. Locations with the highest MR values (hotspots) are likely to contain the actual infection source. The model identified 1 hotspot, located in the southwest of the industrial area, $\approx 650 \mathrm{~m}$ from the BWTP (Figure 2).

To prevent further Legionella transmission by aerosols, 2 temporary tents were erected successively to cover the 2 aerated ponds, 1 in December 2017 and the other in January 2018. A permanent solution for covering both aeration ponds is under exploration. After the

\begin{tabular}{|c|c|c|c|}
\hline \multirow[b]{2}{*}{ Characteristic } & \multicolumn{3}{|c|}{ No. (\%) } \\
\hline & Cluster $1, n=6$ & Cluster $2, n=8$ & Clusters 1 and $2, \mathrm{~N}=14$ \\
\hline \multicolumn{4}{|l|}{ Patient characteristics } \\
\hline Median age $>72$ y & & & $5(35.7)$ \\
\hline Sex & & & $8(57.1)$ \\
\hline M & & & $8(57.1)$ \\
\hline $\mathrm{F}$ & & & $6(42.9)$ \\
\hline Smoking & & & $7(50.0)$ \\
\hline Co-morbid conditions & & & $11(78.6)$ \\
\hline Hospital admission & & & $14(100)$ \\
\hline \multicolumn{4}{|l|}{ ICU admission } \\
\hline Death & & & 0 \\
\hline \multicolumn{4}{|l|}{ Diagnostic results } \\
\hline Legionella culture performed & & & $6(42.9)$ \\
\hline LP sg1 culture positive & & & $5(35.7)$ \\
\hline Urine antigen test positive & & & $14(100)$ \\
\hline LP PCR positive & & & $4 \dagger$ \\
\hline \multicolumn{4}{|l|}{ Typing results } \\
\hline ST1646 & $2(33.3)$ & $3(37.5)$ & $5(35.7)$ \\
\hline Non-ST1646‡ & $2(33.3)$ & 0 & $2(14.3)$ \\
\hline No isolate & $2(33.3)$ & $5(62.5)$ & $7(50.0)$ \\
\hline
\end{tabular}

*Sources: National Notification Database Osiris; Database National Reference Laboratory for Legionella, Haarlem, the Netherlands. ICU, intensive-care unit; LP, Legionella pneumophila; ST, sequence type.

†Number of PCR tests performed is not available; only number of tests with positive results known.

fObtained through nested PCR with direct sequence-based typing. 
Table 2. Results of environmental samples taken during investigation of 2 community clusters of Legionnaires' disease directly linked to a biologic wastewater treatment plant, Boxtel, the Netherlands, October 2016-December $2017^{*}$

\begin{tabular}{|c|c|c|c|c|}
\hline \multirow{2}{*}{ Location of samples } & \multirow[b]{2}{*}{ Sampling date, wk/y } & \multicolumn{3}{|c|}{ Legionella pneumophila } \\
\hline & & CFU/L & serogroup & ST \\
\hline \multicolumn{5}{|l|}{ Water samples $†$} \\
\hline \multicolumn{5}{|l|}{ BWTP } \\
\hline \multirow[t]{2}{*}{ Pond 1 (low aeration) } & $48 / 2017$ & $2.0 \times 10^{6}$ & sg1 & $\ddagger$ \\
\hline & $50 / 2017$ & $5.6 \times 10^{7}$ & sg1 & ST1646 \\
\hline \multirow[t]{2}{*}{ Pond 2 (no aeration) } & $48 / 2017$ & $7.1 \times 10^{8}$ & sg1 & ST1646 \\
\hline & $50 / 2017$ & $19.2 \times 10^{8}$ & sg1 & ST1646 \\
\hline \multirow{2}{*}{ Pond 3 (high aeration) } & $48 / 2017$ & $15.0 \times 10^{8}$ & sg1 & ST1646 \\
\hline & $50 / 2017$ & $22.6 \times 10^{8}$ & sg1 & $\ddagger$ \\
\hline \multicolumn{5}{|l|}{ Municipal wastewater treatment plant } \\
\hline Influent & $39 / 2017$ & $1.0 \times 10^{5}$ & sg1 & ST1646 \\
\hline Pond & $39 / 2017$ & $2 \times 10^{3}$ & sg1 & ST1646 \\
\hline River midstream & $39 / 2017$ & $2 \times 10^{3}$ & sg1 & ST1646 \\
\hline Riverside & $39 / 2017$ & $2 \times 10^{4}$ & sg1 & ST1646 \\
\hline \multirow{2}{*}{ Fountain, city center } & $50 / 2016$ & Negative & & \\
\hline & $39 / 2017$ & Negative & & \\
\hline \multicolumn{5}{|c|}{ WCTs and air scrubbers next to BWTP, industrial area } \\
\hline & $50 / 2016$ & Negative & & \\
\hline & $39 / 2017$ & Negative & & \\
\hline & $48 / 2017$ & Negative & & \\
\hline 4 WCTs, industrial area & $50 / 2016$ & Negative & & \\
\hline 5 WCTs, industrial area & $39 / 2017$ & Negative & & \\
\hline Misting device, industrial area & $39 / 2017$ & Negative & & \\
\hline \multicolumn{5}{|l|}{ Other environmental samples $\dagger$} \\
\hline \multicolumn{5}{|l|}{ Biologic wastewater treatment plant } \\
\hline Air sample inside pond 3 tent & $50 / 2017$ & Positive & sg1 & $\ddagger$ \\
\hline Swab inner surface pond 3 tent & $50 / 2017$ & Positive & sg1 & ST1646 \\
\hline \multicolumn{5}{|c|}{$\begin{array}{l}\text { *Source: Database National Reference Laboratory for Legionella, Haarlem, the Netherlands. BWTP, biologic wastewater treatment plant; sg, serogroup; } \\
\text { ST, sequence type; WCT, wet cooling tower. } \\
\text { tWater samples were analyzed with an accredited in-house developed method based on ISO 11731:2017, with an additional step of acid treatment. Air } \\
\text { samples were collected using a SASS } 2300 \text { air sampler (Research International, Seattle, WA, USA) and analyzed with an accredited in-house developed } \\
\text { method based on ISO } 11731: 2017 \text {. } \\
\text { ‡Sequence type profile was incomplete because of technical problems experienced during mompS typing; however, for all } 6 \text { available alleles, results } \\
\text { were in accordance with the ST1646 profile (flaA, 2; pile, 10; asd, 14; Mip, 10; mompS, not available; proA, 4; neuA, 11). }\end{array}$} \\
\hline
\end{tabular}

detection of Legionella in the BWTP effluent, a sludge filter defect was identified and repaired. Resampling of the effluent was negative for Legionella, indicating that the risk for ongoing contamination of the MWTP and river were reduced.

\section{Discussion}

The LD outbreak in Boxtel occurred in 2 distinct small clusters, rather than a more typical single cluster of cases in a short period. However, the increased LD incidence in the town compared with historical values and the matching sequencing results of clinical isolates suggested a common source for both clusters.

The sequence type ST1646, found in 5 patient isolates and in the environmental samples, identified the BWTP as the most likely source for both LD clusters. Since 2013, this rare sequence type has been detected in 7 other cases in the same region and 2 cases elsewhere in the Netherlands (3). ST1646 has not previously been detected in environmental samples (3). We were unable to epidemiologically link the other ST1646 cases to Boxtel.

The transmission models outcome, which posited a single hotspot near the BWTP, offers further support for the BWTP as the putative source of infection. The distance of the hotspot, at $\approx 650 \mathrm{~m}$, is well within the range of a possible source calculated with this model in a previous study (5).

Two other clinical strains from cluster 1 were not found in any environmental sample. However, the aeration ponds might have harbored different genotypes. Detection of multiple genotypes causing LD cases from exposure to a single water treatment plant has been previously described (6).

BWTPs have been identified as the source of previous LD outbreaks (6-10). Several risk factors for amplification and transmission of Legionella were present in the Boxtel BWTP: a water temperature around $35^{\circ} \mathrm{C}$, nutrient-rich water, and aerosol formation through aeration.

Documented outbreaks associated with BWTPs have involved an additional disseminator, such as a WCT or river, in the dissemination of contaminated aerosols, usually marked by a sudden increase in cases. In this outbreak, we assume direct dispersion of bacteria from the BWTP ponds to the patients, which could explain the sporadic nature of the epidemic curve, with $0-2$ cases per week spread over 2 periods of 8-16 weeks. 


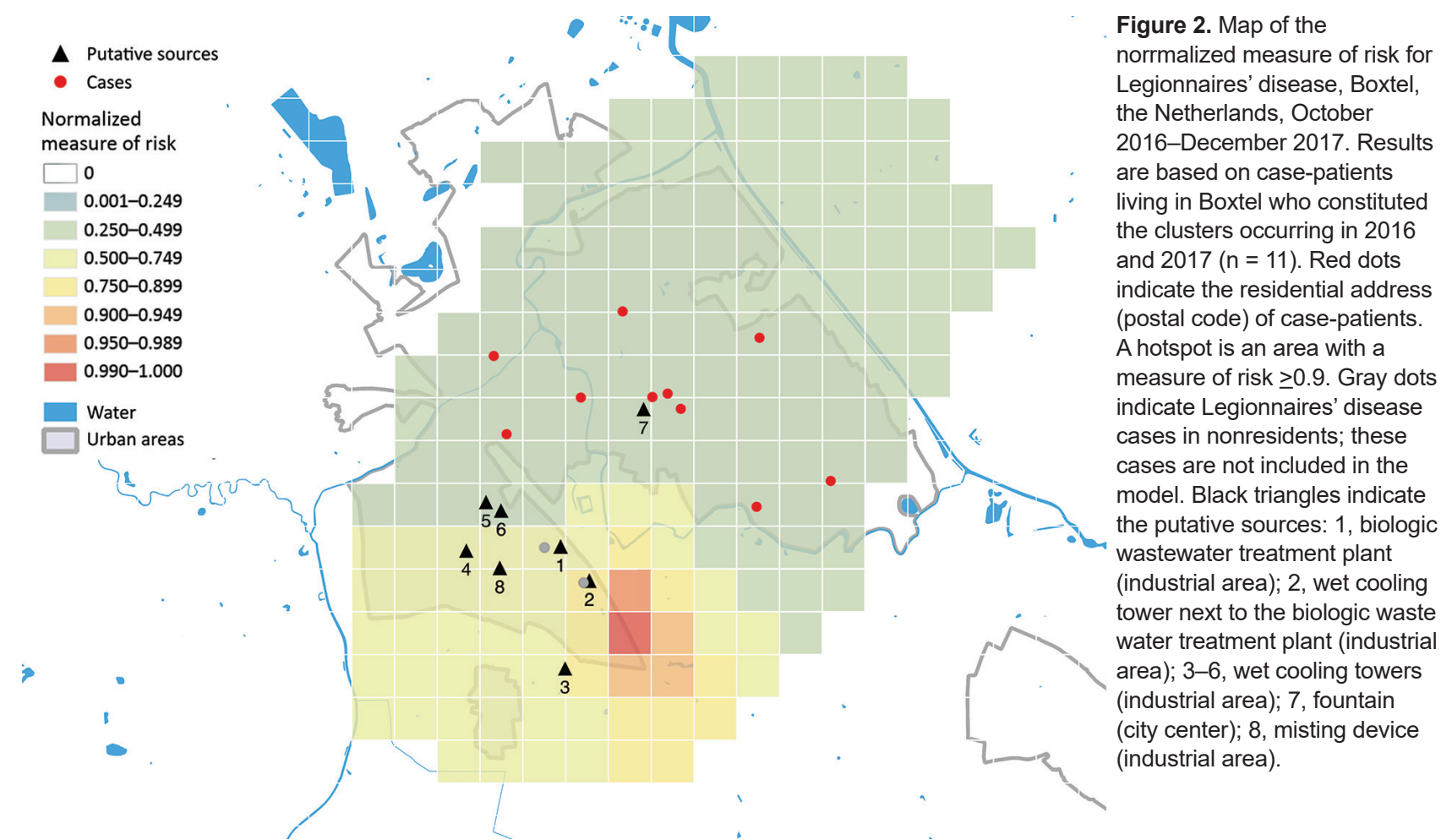

Transmission from WCTs has been described as occurring at a distance of up to $12 \mathrm{~km}$ (11), whereas direct aerosol dispersal from BWTPs has been detected at a distance of up to $300 \mathrm{~m} \mathrm{(8)}$. In this outbreak, the assumed bacteria transmission from the BWTP ponds to the patients occurred over a distance of $\geq 1.6 \mathrm{~km}$. Transmission directly from the elevated aeration ponds is plausible with prevailing wind direction. However, we cannot exclude the possibility that WCTs, air scrubbers, or both in the vicinity of the BWTP disseminated L. pneumophila-containing aerosols, although test results for these installations were negative.

Although incidence of community-acquired LD has increased in the Netherlands since 2013 (12), infection sources are rarely found (13). Because our results indicate direct dispersal over a large distance of $\geq 1.6 \mathrm{~km}$, further investigations should consider nontraditional Legionella sources, like BWTPs, as possible sources for sporadic LD cases.

The aeration ponds in Boxtel were covered, but whether this measure is sufficient to mitigate all exposure risks involved with this type of installation is still unclear. Because biologic aeration ponds are increasingly used in modern (energy-producing) wastewater treatment installations in the Netherlands, more evaluation is required for the potential health risks associated with BWTPs.

\section{Acknowledgments}

A special thanks goes to Diany Stoel for her contribution in identifying environmental sources. We are also grateful for the contribution of the public health nurses from the Municipal Health Service Hart voor Brabant for collecting detailed information on locations visited by the patients and to Joost van der Steen for source finding information on ST1646 cases in the region administered by Municipal and Regional Health Service Brabant-Zuidoost. We thank the medical microbiologists for sending the clinical isolates for SBT. We thank all the persons from the Regional Public Health Laboratory Kennemerland, Haarlem, involved in sampling all the potential sources and for culturing the environmental samples and performing the SBT. We gratefully acknowledge the contribution of Lisa Hansen and her useful and constructive suggestions on this paper.

This work was funded by the regular budget of the Centre for Infectious Disease Control Netherlands at the National Institute for Public Health and the Environment. The funding source had no involvement in the study design and the preparation, review, or approval of the manuscript.

\section{About the Author}

Ms. Loenenbach is a fellow at the European Programme for Intervention Epidemiology Training and is based at the National Institute for Public Health and Environment, the Netherlands. Her primary research interests include infectious disease epidemiology, social anthropology, and gender studies. 


\section{References}

1. European Centre for Disease Prevention and Control. European Legionnaires' Disease Surveillance Network (ELDSNet)operating procedures for the surveillance of travel-associated Legionnaires' disease in the EU/EEA. Stockholm: European Centre for Disease Prevention and Control; 2017.

2. Ratzow S, Gaia V, Helbig JH, Fry NK, Lück PC. Addition of neuA, the gene encoding $\mathrm{N}$-acylneuraminate cytidylyl transferase, increases the discriminatory ability of the consensus sequencebased scheme for typing Legionella pneumophila serogroup 1 strains. J Clin Microbiol. 2007;45:1965-8. http://dx.doi.org/ 10.1128/JCM.00261-07

3. Gaia V, Fry NK, Afshar B, Lück PC, Meugnier H, Etienne J, et al. Consensus sequence-based scheme for epidemiological typing of clinical and environmental isolates of Legionella pneumophila. J Clin Microbiol. 2005;43:2047-52. http://dx.doi.org/10.1128/ JCM.43.5.2047-2052.2005

4. Schimmer B, Ter Schegget R, Wegdam M, Züchner L, de Bruin A, Schneeberger PM, et al. The use of a geographic information system to identify a dairy goat farm as the most likely source of an urban Q-fever outbreak. BMC Infect Dis. 2010;10:69. http://dx.doi.org/10.1186/1471-2334-10-69

5. van Leuken JP, Havelaar AH, van der Hoek W, Ladbury GA, Hackert VH, Swart AN. A model for the early identification of sources of airborne pathogens in an outdoor environment. PLoS One. 2013;8:e80412. http://dx.doi.org/10.1371/ journal.pone. 0080412

6. Kusnetsov J, Neuvonen LK, Korpio T, Uldum SA, Mentula S, Putus T, et al. Two Legionnaires' disease cases associated with industrial waste water treatment plants: a case report. BMC Infect Dis. 2010;10:343. http://dx.doi.org/10.1186/1471-2334-10-343

7. Blatny JM, Reif BA, Skogan G, Andreassen O, Høiby EA, Ask E, et al. Tracking airborne Legionella and Legionella pneumophila at a biological treatment plant. Environ Sci Technol. 2008;42:7360-7. http://dx.doi.org/10.1021/es800306m

8. Olsen JS, Aarskaug T, Thrane I, Pourcel C, Ask E, Johansen G, et al. Alternative routes for dissemination of Legionella pneumophila causing three outbreaks in Norway. Environ Sci Technol. 2010;44:8712-7. http://dx.doi.org/10.1021/es1007774

9. Nygård K, Werner-Johansen Ø, Rønsen S, Caugant DA, Simonsen Ø, Kanestrøm A, et al. An outbreak of legionnaires disease caused by long-distance spread from an industrial air scrubber in Sarpsborg, Norway. Clin Infect Dis. 2008;46:61-9. http://dx.doi.org/10.1086/524016

10. van Heijnsbergen E, Schalk JA, Euser SM, Brandsema PS, den Boer JW, de Roda Husman AM. Confirmed and potential sources of Legionella reviewed. Environ Sci Technol. 2015;49:4797-815. http://dx.doi.org/10.1021/acs.est.5b00142

11. Walser SM, Gerstner DG, Brenner B, Höller C, Liebl B, Herr CE. Assessing the environmental health relevance of cooling towers - a systematic review of legionellosis outbreaks. Int J Hyg Environ Health. 2014;217:145-54. http://dx.doi.org/ 10.1016/j.ijheh.2013.08.002

12. Rijksinstituut voor Volksgezondheid en Milieu. Legionella webpagina [in Dutch] [cited 2018 Jul 5]. https://www.rivm.nl/ Onderwerpen/L/Legionella/Legionella_webpagina1

13. Den Boer JW, Euser SM, Brandsema P, Reijnen L, Bruin JP. Results from the National Legionella Outbreak Detection Program, the Netherlands, 2002-2012. Emerg Infect Dis. 2015;21:1167-73. http://dx.doi.org/10.3201/eid2107.141130

Address for correspondence: Anna D. Loenenbach, Rijksinstituut voor Volksgezondheid en Milieu Antonie van Leeuwenhoeklaan 9, 3721 MA Bilthoven, Bilthoven 3720 BA, the Netherlands; email: aloenenbach@gmail.com

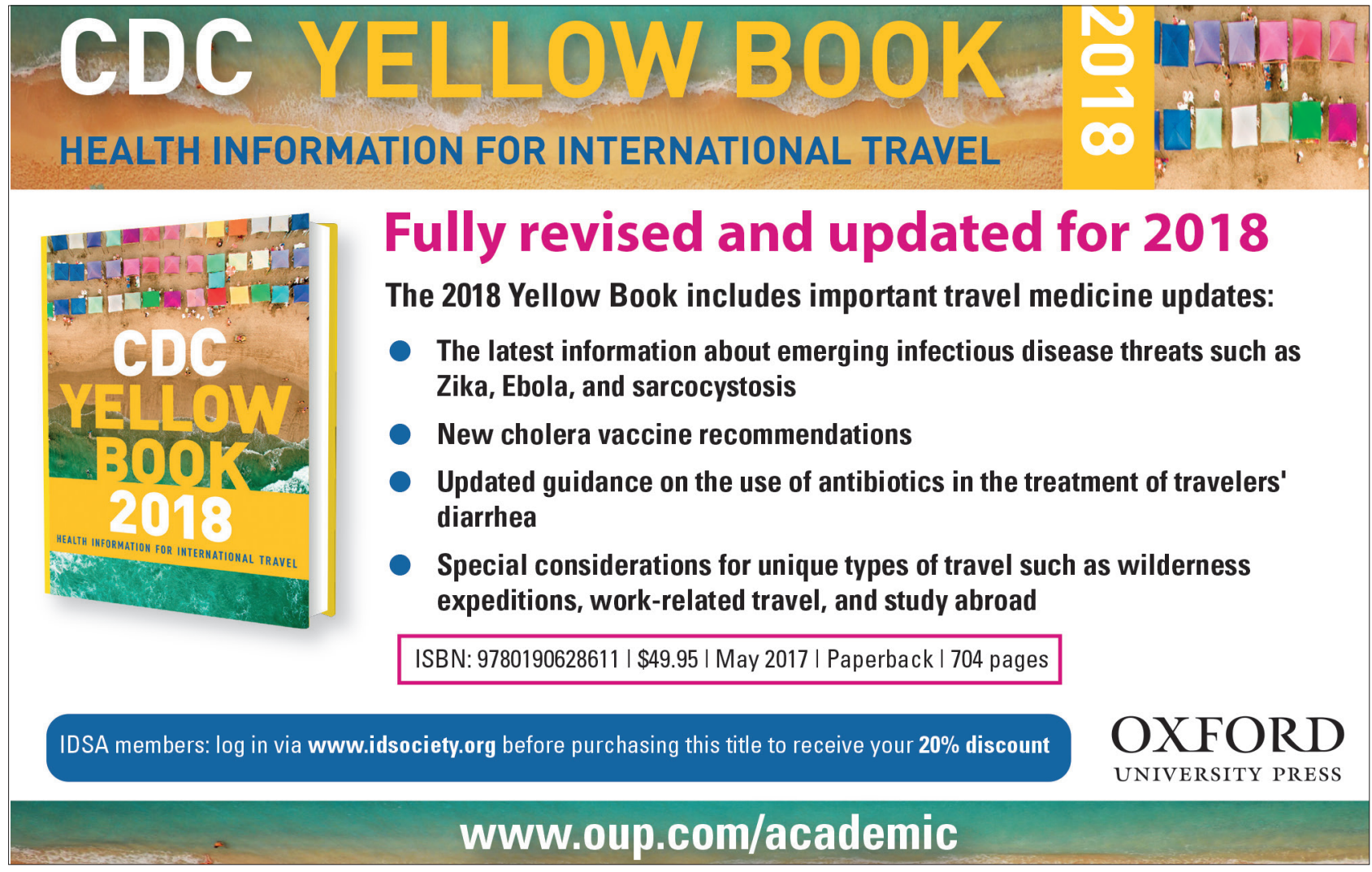

